\title{
Atitude do professor em relação à estatística: um estudo de caso utilizando a ferramenta EAPE
}

Teacher attitude on statistics: a case study using the EAPE tool

\author{
Ricardo Alberti', Bruna Freitas dos Santos", Fernado de Jesus Moreira Junior'II
}

\begin{abstract}
RESUMO
As atitudes dos professores influenciam tanto em sala de aula, como também fora dela, por meio das expectativas deles em relação aos alunos, quanto também ao comportamento em relação aos mesmos. O objetivo desse artigo é conhecer as atitudes de professores do Departamento de Estatística de uma Universidade do sul do Brasil, utilizando a Escala de Atitude de Professores de Estatística (EAPE) e sua versão atualizada, a EAPE15. Essa pesquisa classifica-se como descritiva e exploratória. Utilizou-se da EAPE e da EAPE15 em um estudo de caso onde os dados foram analisados através das análises descritiva e de correlação. $O$ estudo demonstrou que os professores têm atitudes favoráveis ao ensino da estatística envolvendo todos os domínios de analise das ferramentas EAPE e EAPE15.
\end{abstract}

Palavras-chave: Estatística; Ensino; Atitude; EAPE.

\begin{abstract}
Teachers' attitudes influence both in and outside the classroom through their expectations of students as well as their behavior. The purpose of this article is to know the attitudes of professors of the Statistics Department of a University of south of Brazil, using the Statistical Teachers Attitude Scale (EAPE) and its updated version, the EAPE15. This research is classified as descriptive and exploratory. EAPE and EAPE15 were used in a case study where the data were analyzed through descriptive and correlation analysis. Finally, the study showed that teachers have favorable attitudes towards teaching statistics involving all domains of analysis of the EAPE and EAPE15.
\end{abstract}

Keywords: Statistics; Teaching; Attitude; EAPE. 


\section{INTRODUÇÃO}

Os professores, aqueles que ensinam, que transmitem o seu conhecimento, são peças fundamentais na vida do aluno enquanto sua formação ao longo dos anos, sendo ele um atuante ativo na formação de um cidadão. As atitudes dos professores influenciam tanto em sala de aula, como também fora dela, por meio das expectativas deles em relação aos alunos, quanto também ao comportamento em relação aos mesmos.

No Brasil, um estudo em relação a professores que ensinam estatística (OLIVEIRA JÚNIOR; 2011), avaliou as atitudes, características pessoais, utilização de tecnologias e práticas docentes de professores de Estatística da única Universidade Privada do Distrito Federal, Universidade Católica de Brasília em relação à Estatística buscando indicar informações para auxiliar no processo ensino-aprendizagem da Estatística.

Cazorla et al. (1999), definem a atitude em relação à Estatística como a resposta afetiva dada por um indivíduo diante de uma situação em que irá utilizar seu conteúdo, seja cursando uma disciplina ou analisando dados de uma pesquisa. A atitude por ser um construto, não pode ser medida diretamente, sendo necessário utilizar instrumentos que possam medir as variáveis secundárias que estão relacionadas com este construto.

Oliveira Junior e Moraes (2009), mediante ao fato da matéria de estatística ser considerada uma das disciplinas mais difíceis de muitos cursos de graduação, iniciaram uma longa pesquisa que resultou em uma ferramenta que tem a finalidade de medir as atitudes de professores de estatística.

Estrada, Batanero e Fortuny (2003) distinguem dois tipos de componentes nas atitudes: componentes pedagógicos e antropológicos. Entre os pedagógicos, mencionam: a) componente cognitivo, que são expressões do pensamento; b) componente afetivo, que são expressões de sentimento, e c) componente de conduta, que são componentes vinculados às atuações em relação ao objeto das atitudes. Por outro lado, os componentes antropológicos são: a) componente social, que são as atitudes relacionadas com a percepção e valorização do papel da Estatística no âmbito sociocultural; b) componente educativo, que é o interesse em relação à Estatística e sua 
aprendizagem, e c) componente instrumental, que é a utilidade da Estatística em relação às outras disciplinas como forma de raciocínio e como componente cultural. Esses componentes serviram de base para a elaboração da versão atualizada a Escala EAPE15, a qual permite analisar segundo a ótica dos seis domínios que são: valorização, afetividade, ensino, conteúdo, método e abstração.

Dessa forma, esta pesquisa visou conhecer as atitudes de professores do Departamento de Estatística de uma Universidade do sul do Brasil, utilizando a ferramenta EAPE (Escala de Atitude de Professores de Estatística), proposta por Oliveira Junior e Morais (2009), e sua versão atualizada EAPE15, proposta por Oliveira Junior (2011). Esse estudo justifica-se pela necessidade de conhecer as atitudes dos professores em relação à Estatística, identificando as atitudes positivas ou menos positivas que possam contribuir na formação de um Estatístico.

\section{FUNDAMENTAÇÃO TEÓRICA}

Para Estrada (2011) a Estatística é um componente indispensável na educação onde professores desempenham um papel no processo de ensino. Em 2009, Oliveira Júnior e Morais (2009), construíram a Escala de Atitude de Professores de Estatística (EAPE) que foi segundo os próprios autores uma das primeiras tentativas brasileiras de se mensurar atitudes positivas frente ao Ensino de Estatística e teria como base quatro fatores: Cognitivo; Afetivo e social; Educativo; Conduta.

Inicialmente a escala continha 42 itens, mas foi reduzida à 21 itens medidos na escala Likert (LIKERT, 1932), durante seu estudo os pesquisadores em caráter exploratório validaram a ferramenta com uma amostra de 87 professores que ministravam a disciplina de estatística em diversas áreas em sete estados brasileiros, todavia o processo foi baseado em uma amostra relativamente pequena o que motivou a realização de um novo estudo para construir e discutir a confiabilidade e validade de uma escala de atitudes de professores baseada no refinamento da EAPE de 21 itens a partir de uma amostra com maior número de professores (Oliveira Junior, 2016, p. 1452).

Dessa forma, Oliveira Junior (2016) buscou através de uma revisão bibliográfica e documental possíveis artigos que poderiam servir como base para o refinamento da 
ferramenta. O estudo de Carmona (2004) trás uma revisão sobre as atitudes e ansiedades em relação à Estatística, no artigo o autor encontra 112 trabalhos que utilizam medida desses construtos e utilizando 17 instrumentos.

Entre os principais estudos que abordam atitudes de professores em relação à estatística estão os seguintes trabalhos: Survey of Attitudes Toward Statistics de Schau et al. (1995), Attitudes Toward Statistics de Wise (1985), Actitud hacia la Estadística de Auzmendi (1992), Escala de atitudes em relação à estatística de Cazorla et al. (1999), Statistics Attitude Survey de Roberts e Bilderback (1980), Students Attitudes Toward Statistics de Sutarso (1992), Statistics Attitude Scale de McCall, Belli e Madjidi (1991), Attitude Toward Statistics de Miller et al. (1993), Quantitative Attitudes Questionnaire de Chang (1996), Escala de Atitudes em relação à Estatística de Velandrino e Parodi (1999).

Para Tishkovskaya e Lancaster (2012) além de melhorar o ensino e aprendizagem, é necessário melhorar as atitudes em relação à Estatística. Martins (2015) corrobora que as atitudes e os comportamentos dos professores na sala de aula influenciam diretamente na atitude dos alunos que poderão tem atitudes (positivas ou negativas) e com consequências no seu rendimento e motivação. Na Figura 1, Martins (2015) demonstra como e o ciclo com relação à estatística mediante as atitudes por parte do professor.

Figura 1 - Ciclo preliminar da Atitude do professor em relação à Estatística

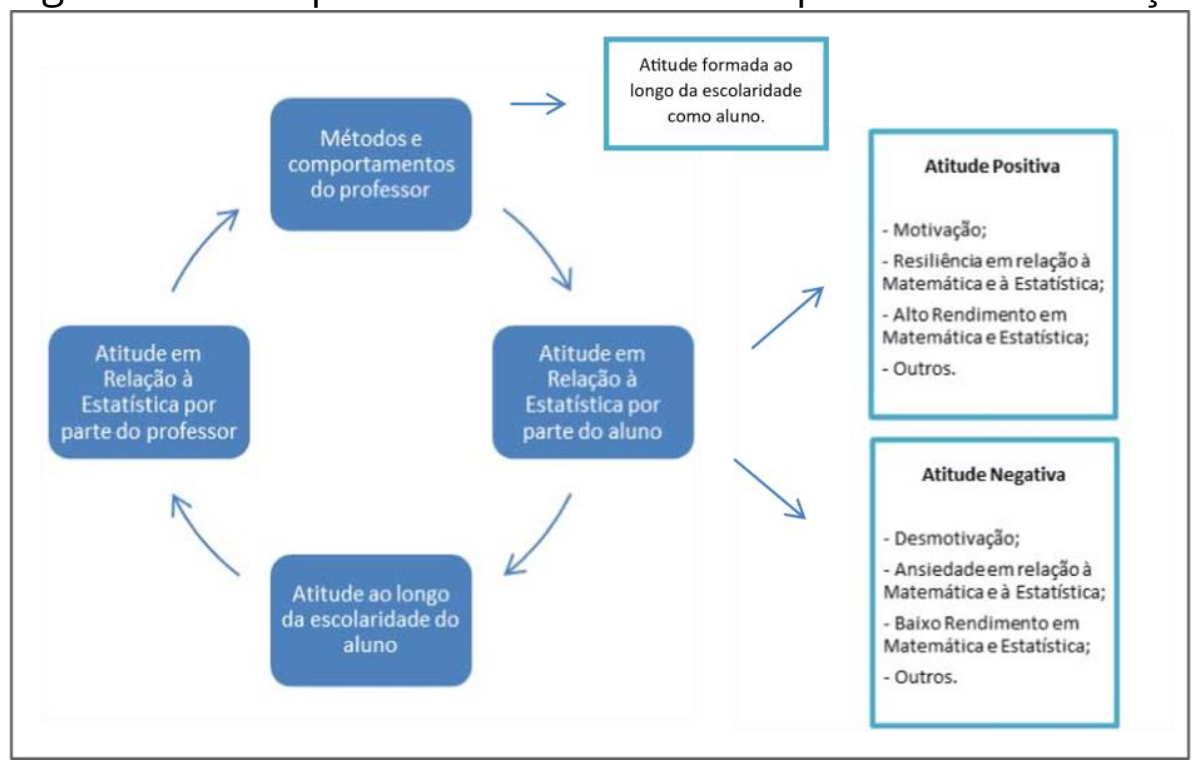

Fonte: Adaptado de Martins (2015, p. 145). 
Na Figura 1 proposta por Martins (2015), é perceptível que os métodos e comportamentos do professor estão diretamente ligados às atitudes que ele tinha enquanto aluno e essas implicam diretamente na atitude em relação à estatística dos seus alunos, que pode ser positiva ou negativa. Só será possível para os alunos entenderem os conceitos e construírem um ciclo de atitude positiva mediante a influência do professor demonstrado por suas atitudes.

Para muitos autores como Gal e Ginsburg (1994), Estrada, Batanero e Lancaster (2011) assim como para Oliveira Junior (2016) o estudo das atitudes dos professores em relação à Estatística é importante, por dois motivos: pela influência no processo educativo e pelo resultado formativo que daí resulta. Estrada, Batanero e Lancaster (2011) acreditam que existe relação dos professores com a experiência que tiveram como alunos, e enquanto profissionais, que molda suas atitudes, e essas por consequência influenciarão a aprendizagem dos seus alunos.

Segundo Oliveira Junior e Moraes (2009, p. 582) "As atitudes dos professores afetam o ensino e os alunos, pois essas influenciam tanto as expectativas deles em relação aos alunos quanto o comportamento em relação aos mesmos". Defronte ao que foi apresentado, Oliveira Junior (2016) buscou refinar a EAPE e em 2016 realizou novamente uma coleta de dados, dessa vez com 334 professores que ministravam as disciplinas de estatística e foi respondida por professores de todos os estados brasileiros, Abaixo está disposto no Quadro 1, a distribuição dos professores de estatística por região e área na qual ministram a disciplina.

Quadro 1 - Distribuição de Professores no Refinamento da EAPE

\begin{tabular}{|l|c|c|c|c|c|c|c|c|}
\hline & \multicolumn{2}{|c|}{ Global } & \multicolumn{2}{c|}{ Exatas } & Humanas & \multicolumn{2}{c|}{ Saúde } \\
\hline & $334(100,0)$ & 116 & $(35,7)$ & 135 & $(41,5)$ & \multicolumn{2}{c|}{$74(22,8)$} \\
\hline Região & $\mathrm{n}$ & $\%$ & $\mathrm{n}$ & $\%$ & $\mathrm{n}$ & $\%$ & $\mathrm{n}$ & $\%$ \\
\hline Centro Oeste & 47 & 14,1 & 12 & 10,3 & 23 & 17 & 12 & 16,2 \\
\hline Norte & 27 & 8,1 & 7 & 6 & 15 & 11,1 & 5 & 6,8 \\
\hline Nordeste & 63 & 18,9 & 23 & 19,8 & 24 & 17,8 & 15 & 20,3 \\
\hline Sul & 92 & 27,5 & 34 & 29,3 & 36 & 26,7 & 17 & 23 \\
\hline Sudeste & 105 & 31,4 & 40 & 34,5 & 37 & 27,4 & 25 & 33,8 \\
\hline Fonte: Oliveira Junior (2016, p. 1457).
\end{tabular}


Pode ser percebido através do Quadro 1, que os professores da amostra são os que ministravam a disciplina somente em três áreas: ciências exatas, humanas e saúde. Nesta etapa da pesquisa, Oliveira Junior (2016) analisou os fatores com relação aos componentes pedagógicos que são diferenciados nos estudos de Auzmendi (1992), Gil Flores (1999) e Gómez Chacón (2000), os autores concordam que existam três fatores básicos nas atitudes, assim como no Quadro 2, e alinhando aos componentes antropológicos utilizados anteriormente na EAPE que, segundo Estrada, Bazán e Aparício (2013), representam o conceito pluridimensional das atitudes dos professores em relação à Estatística, disponíveis no Quadro 3.

\section{Quadro 2 - Componentes Pedagógicos}

\begin{tabular}{|l|l|}
\hline $\begin{array}{l}\text { Componente afetivo } \\
\text { ou emocional }\end{array}$ & $\begin{array}{l}\text { Refere-se às emoções e sentimentos que despertam a Estatística, sendo mais } \\
\text { subjetivas; por exemplo, sentimento de rejeição ou de interesse; }\end{array}$ \\
\hline $\begin{array}{l}\text { Componente } \\
\text { cognitivo }\end{array}$ & $\begin{array}{l}\text { Refere-se às concepções e crenças, acerca do objeto atitudinal, neste caso, a } \\
\text { Estatística; }\end{array}$ \\
\hline $\begin{array}{l}\text { Componente } \\
\text { comportamental }\end{array}$ & $\begin{array}{l}\text { Representam a tendência da ação ou intenção de uma maneira determinada, por } \\
\text { exemplo, como e quando se usaria a Estatística. }\end{array}$ \\
\hline
\end{tabular}

Fonte: Adaptado de Oliveira Junior (2016).

\section{Quadro 3 - Componentes Antropológicos}

\begin{tabular}{|l|l|}
\hline $\begin{array}{l}\text { Componente } \\
\text { social: }\end{array}$ & $\begin{array}{l}\text { São atitudes relacionadas com a percepção e valoração do papel da Estatística no âmbito } \\
\text { sociocultural de qualquer cidadão; }\end{array}$ \\
\hline $\begin{array}{l}\text { Componente } \\
\text { educativo: }\end{array}$ & $\begin{array}{l}\text { Neste componente o interesse em relação à Estatística é sua aprendizagem, a visão de } \\
\text { sua utilidade para o aluno, sua opinião sobre se deverá ser incluída no currículo e a } \\
\text { dificuldade percebida; }\end{array}$ \\
\hline $\begin{array}{l}\text { Componente } \\
\text { instrumental: }\end{array}$ & $\begin{array}{l}\text { É aqui considerada a utilidade de outros materiais como uma maneira de pensar e como } \\
\text { um componente cultural. A introdução destes novos componentes fornecerá todas as } \\
\text { questões relativas à utilidade, a formação e multidisciplinaridade da Estatística e } \\
\text { também todos aquelas que se relacionam diretamente com o contexto social e cultural. }\end{array}$ \\
\hline
\end{tabular}

Fonte: Adaptado de Oliveira Junior (2016).

Com base nos componentes pedagógicos e antropológicos a EAPE realiza uma combinação entre eles para alinhar as vinte e uma questões do instrumento. A escala EAPE utiliza uma escala Likert com cinco níveis (Concordo Totalmente; Concordo Parcialmente; Indiferente; Discordo Parcialmente; Discordo Totalmente) e com proposições positivas e negativas. Dessa maneira a escala utilizada compreende os seguintes itens (Quadro 4). 
Quadro 4 - Questões da EAPE

\begin{tabular}{|l|l|}
\hline \multicolumn{1}{|c|}{ Código } & Descrição \\
\hline V1 & $\begin{array}{l}\text { É divertido lecionar estatística; } \\
\text { teoria e a prática; }\end{array}$ \\
\hline V2 & Fazer perguntas aos alunos durante as aulas ajuda na apreensão do conteúdo; \\
\hline V3 & $\begin{array}{l}\text { Não me parece importante relacionar novos conhecimentos com conteúdo anteriormente } \\
\text { aprendidos; }\end{array}$ \\
\hline V4* & $\begin{array}{l}\text { Os alunos devem estar conscientes da importância do conhecimento matemático para a } \\
\text { aprendizagem da Estatística; }\end{array}$ \\
\hline V5 & A aprendizagem da Estatística não pressupõe conhecimentos matemáticos; \\
\hline V7* & A representação gráfica não facilita a compreensão dos resultados estatísticos; \\
\hline V8 & Motivar os alunos ajuda na aprendizagem da Estatística; \\
\hline V9 & $\begin{array}{l}\text { O pensamento estatístico é tão necessário para a cidadania eficiente como saber ler e } \\
\text { escrever; }\end{array}$ \\
\hline V10* & Podemos manipular a realidade através da Estatística; \\
\hline V11 & Respondo com maturidade quando meus alunos fazem uma pergunta; \\
\hline V12 & É importante apresentar conceitos básicos da Estatística Bayesiana; \\
\hline V13 & Devo desenvolver atividades com dados reais utilizando minha experiência; \\
\hline V14 & Vinculo a Estatística aos métodos e técnicas científicas; \\
\hline V15 & $\begin{array}{l}\text { Estudo e procuro explicações lógicas que comprovem as imprecisões apresentadas por } \\
\text { autores de livros de Estatística; }\end{array}$ \\
\hline V16* & Evito as informações estatísticas quando as leio; \\
\hline V17* & Evito ler artigos científicos onde são apresentados resultados estatísticos; \\
\hline V18 & Procuro diferentes maneiras de resolver um problema de Estatística; \\
\hline V19 & Gosto da Estatística porque ela ajuda a solucionar problemas objetivamente; \\
\hline V20 & A Estatística me ajuda a entender mais profundamente a complexidade de certos temas; \\
\hline V21* & Utilizo a Estatística exclusivamente para dar aulas. \\
\hline & Fonte: Adaptado de Oliveira Junior (2016, p. 1455). \\
\hline
\end{tabular}

(*) Proposições negativas

Com base em cada afirmativa é possível analisar uma combinação entre um componente pedagógico e um antropológico, como mostra o quadro 5.

Quadro 5 - Componentes das atitudes avaliadas na escala EAPE

\begin{tabular}{|l|c|c|c|}
\hline \multirow{2}{*}{ Componente Pedagógico } & \multicolumn{3}{|c|}{ Componente Antropológico } \\
\cline { 2 - 4 } & Social & Educativo & Instrumental \\
\hline Afetivo & 19,21 & 1,8 & 17 \\
\hline Cognitivo & 16 & $2,3,4,5,6,12,13$ & 7,14 \\
\hline Comportamental & 9,10 & 11,18 & 15,20 \\
\hline
\end{tabular}

Fonte: Oliveira Junior (2016, p. 1456).

É oportuno observar que existem alguns itens que são calibrados positivamente (item $1,2,3,5,8,9,11,12,13,14,15,18,19$ e 20) e alguns negativamente (item 4, 6, 7, 10, 16, 17 e 21), isto é, os itens positivos apresentaram a sequência de pesos $1=$ Discordo Totalmente, 2 = Discordo Parcialmente, 3 = Sou Indiferente (não concordo e nem discordo), 4 = Concordo Parcialmente e 5 = Concordo Totalmente; os itens 
negativos apresentaram a sequência de pesos 5 = Discordo Totalmente, $4=$ Discordo Parcialmente, 3 = Sou Indiferente, 2 = Concordo Parcialmente e 1 = Concordo Totalmente (Oliveira Junior, 2016). É oportuno salientar também que para análise dos domínios da ferramenta EAPE15 são desconsideradas as questões 1, 6, 8, 9, 10 e 18 e a EAPE15 segue o seguinte pressuposto descrito no Quadro 6.

Quadro 6 - Domínios das atitudes avaliadas na escala EAPE15

\begin{tabular}{|c|c|c|c|c|c|c|c|}
\hline \multirow{2}{*}{$\begin{array}{c}\text { Item da } \\
\text { Escala EAPE }\end{array}$} & \multirow{2}{*}{$\begin{array}{c}\text { Componente Inicial } \\
\text { da escala EAPE }\end{array}$} & \multicolumn{6}{|c|}{ Domínios da Escala EAPE15 } \\
\hline & & Valorização & Afetividade & Ensino & Conteúdo & Método & Abstração \\
\hline 20 & $\begin{array}{c}\text { Comportamental e } \\
\text { Instrumental }\end{array}$ & $x$ & & & & & \\
\hline 19 & Afetivo e Social & $x$ & & & & & \\
\hline 11 & $\begin{array}{c}\text { Comportamental e } \\
\text { Educativo }\end{array}$ & $\mathrm{X}$ & & & & & \\
\hline 17 & $\begin{array}{c}\text { Afetivo e } \\
\text { Instrumental }\end{array}$ & & $x$ & & & & \\
\hline 16 & Afetivo e Social & & $x$ & & & & \\
\hline 21 & Cognitivo e Social & & $x$ & & & & \\
\hline 2 & $\begin{array}{c}\text { Cognitivo e } \\
\text { Instrumental }\end{array}$ & & & $x$ & & & \\
\hline 13 & $\begin{array}{c}\text { Cognitivo e } \\
\text { Educativo }\end{array}$ & & & $x$ & & & \\
\hline 3 & $\begin{array}{l}\text { Cognitivo e } \\
\text { Educativo }\end{array}$ & & & $x$ & & & \\
\hline 4 & $\begin{array}{l}\text { Cognitivo e } \\
\text { Educativo }\end{array}$ & & & & $x$ & & \\
\hline 7 & $\begin{array}{c}\text { Cognitivo e } \\
\text { Instrumental }\end{array}$ & & & & $x$ & & \\
\hline 14 & $\begin{array}{c}\text { Cognitivo e } \\
\text { Instrumental }\end{array}$ & & & & & $x$ & \\
\hline 15 & $\begin{array}{l}\text { Comportamental e } \\
\text { Instrumental }\end{array}$ & & & & & $x$ & \\
\hline 5 & $\begin{array}{c}\text { Cognitivo e } \\
\text { Educativo }\end{array}$ & & & & & & $x$ \\
\hline 12 & $\begin{array}{l}\text { Cognitivo e } \\
\text { Educativo }\end{array}$ & & & & & & $x$ \\
\hline
\end{tabular}

Fonte: adaptado de Oliveira Junior (2016, p. 1461).

\section{PROCEDIMENTOS METODOLÓGICOS}

Essa pesquisa é classificada como descritiva, exploratória e estudo de caso, pois foi aplicada em docentes do Departamento de Estatística de uma Universidade do sul do Brasil, que conta com um corpo de 21 professores efetivos, segundo a página eletrônica do departamento. Esses professores atendem diversos cursos de graduação e pós-graduação na Universidade, incluindo um Curso de Bacharelado em Estatística 
no período noturno. A pesquisa adota uma abordagem quantitativa, pois é possível através da escala entender quais são as atitudes dos professores no departamento de maneira geral. Todos os professores foram contatados três vezes pelos pesquisadores, sendo uma vez pessoalmente e duas subsequentes via e-mail, no início do segundo semestre de 2019.

O questionário utilizado para a coleta de dados foi a Escala de Atitudes de Professores da Estatística (EAPE), proposta e validada por Oliveira Junior e Morais (2009), e sua versão estendida EAPE15, proposta e validada por Oliveira Junior (2011), além de algumas questões de perfil. A análise de dados se deu através de medidas descritivas, tabelas de frequência, gráficos, correlações e testes de hipóteses para correlações. Foram utilizados os softwares Excel, SPSS e R.

\section{APRESENTAÇÃO E DISCUSSÃO DOS RESULTADOS}

\subsection{Análise descritiva dos dados de perfil}

Na Tabela 1 são apresentadas as análises descritivas de média, mediana, mínimo, máximo, amplitude, variância, desvio padrão, coeficiente de variação, assimetria e curtose da idade, do tempo de atuação docente e da média de alunos por turma. Analisando a Tabela 1, pode-se observar que a média de idade dos Professores de Estatística dessa universidade é 44,38 anos, com idades variando entre 28 e 65 anos. O tempo médio de atuação docente é de 15,88 anos. A média de alunos por turma é de 21,81 alunos. O desvio padrão demonstra certa similaridade nas três variáveis, isso é na idade é de 11,92, tempo de atuação 12,04 e média de alunos 12,32. No entanto, o coeficiente de variação é de 0,26 na idade, 0,73 no tempo de atuação e 0,55 na média de alunos por turma, mostrando uma diferença na variabilidade relativa dessas variáveis.

Tabela 1 - Análises descritivas das perguntas alternativas

\begin{tabular}{lccc}
\hline \multicolumn{4}{c}{ Análises Descritivas } \\
\hline & Idade (anos) & Tempo de Atuação (anos) & Média de alunos por turma \\
\hline Média & 44,38 & 15,88 & 21,81 \\
Mediana & 40,50 & 13,00 & 22,50 \\
Desvio Padrão & 11,92 & 12,04 & 12,32 \\
Coeficiente de Variação & 0,26 & 0,73 & 0,55 \\
\hline \multicolumn{2}{l}{ Fonte: Elaborado pelos autores. }
\end{tabular}


Na Figura 2 é possível perceber a relação de idade do professor e o tempo de atuação docente. A Figura 2 mostra que os professores que estão no início da carreira docente têm entre 25 e 40 anos, os professores que possuem entre 10 e 16 anos de carreira encontram-se entre 40 e 50 anos e os professores acima de 25 anos de carreira têm idade entre 50 e 70 anos. O tempo de carreira e a idade são fortemente correlacionados $(r=0,94)$, sendo esse um resultado esperado nessa análise. Observase, no entanto, que há claramente dois grupos de docentes bem definidos: 16 docentes com até 16 anos de carreira docente e 5 docentes com pelo menos 28 anos de carreira docente.

Figura 2 - Gráfico de dispersão (Variável Idade e Tempo de atuação docente)

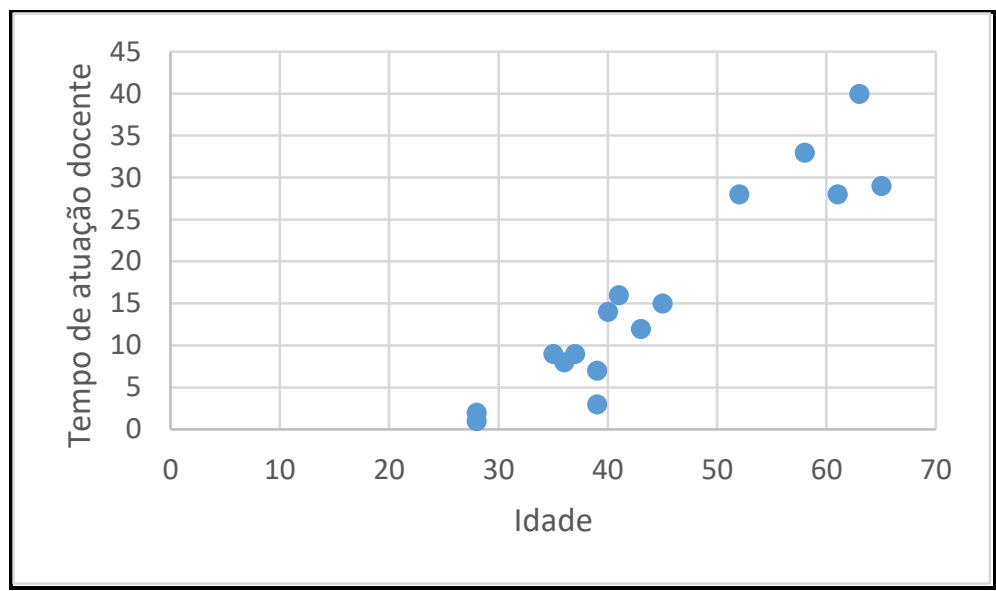

Fonte: Elaborado pelos autores.

A partir da Figura 3 foi possível perceber existe uma relação moderada entre o tempo de atuação docente e a média de número de alunos por turma $(r=0,51)$. Parece haver uma tendência em professores mais experientes possuírem mais alunos nas suas aulas, em média. Isso pode ser explicado por um fato observado pelos pesquisadores durante a aplicação da pesquisa, onde observou-se que as disciplinas do Curso de Bacharelado em Estatística, as quais possuem menos alunos, geralmente são lecionadas pelos professores mais jovens. Ressalta-se um caso de um docente que respondeu não ter nenhum aluno no semestre da realização da pesquisa pois o mesmo se encontrava afastado nesse período. 
Figura 3 - Gráfico de dispersão (Variável Tempo de atuação docente e Média de alunos por turma)

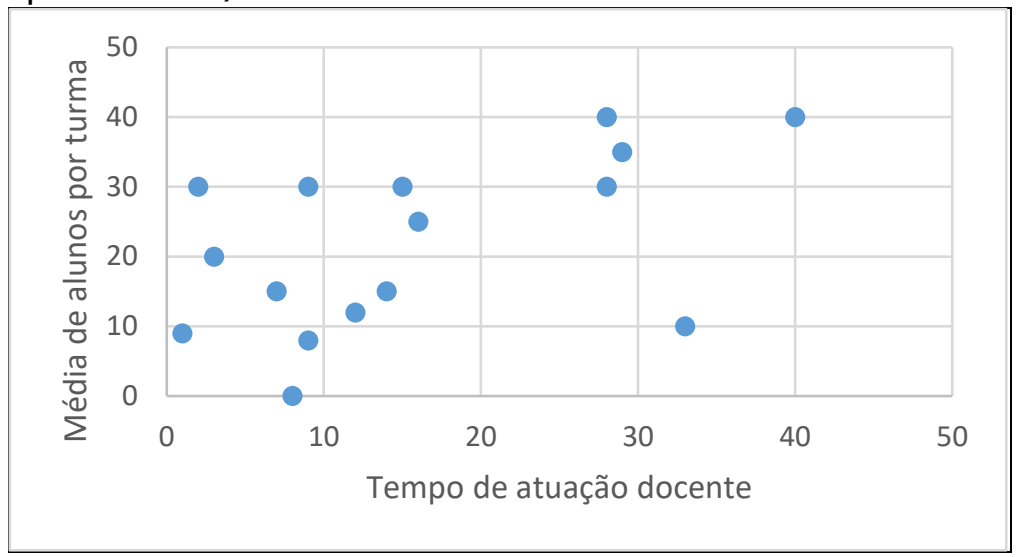

Fonte: Elaborado pelos autores.

Na Tabela 2 é apresentada a relação entre gênero e o estado civil. Na Tabela 2, vê-se que, com relação ao gênero, entre os respondentes, há um número maior de professores do gênero masculino casados $37,5 \%$, seguido por professores também do gênero masculino solteiros $25,00 \%$. A idade média não difere muito entre os homens $(45,00)$ e as mulheres $(43,33)$, nem o tempo médio de atuação docentes, sendo 15,70 para os homens e 16,17 para as mulheres. Porém, quando analisado o estado civil, verifica-se que os professores solteiros possuem em média 36,50 anos, os casados 47,56 anos e a professora divorciada 63 anos. Como observado na Figura 2, o tempo de atuação docente é proporcional à idade, onde os professores solteiros atuam em média há 6,83 anos, os casados há 19,22 anos e a professora divorciada há 40 anos. Os homens possuem uma média de 18,00 alunos por turma, enquanto que as mulheres possuem em média 28,17 alunos por turma. Já os professores solteiros possuem em média 16,83 alunos por turma, os casados 23,11 e a professora divorciada 40.

Tabela 2 - Relação entre gênero e o estado civil

\begin{tabular}{lcccc}
\hline & Solteiro(a) & Casado(a) & Separado(a)/Divorciado(a) & Total \\
\hline Feminino & $2-(12,5 \%)$ & $3-(18,75 \%)$ & $1-(6,25 \%)$ & $6-(37,5 \%)$ \\
Masculino & $4-(25 \%)$ & $6-(37,5 \%)$ & 0 & $10-(62,5 \%)$ \\
Total & $6-(37,5 \%)$ & $9-(56,25 \%)$ & $1-(6,25 \%)$ & $16-(100 \%)$ \\
\hline \multicolumn{2}{r}{ Fonte: Elaborado pelos autores. }
\end{tabular}

\subsection{Análise descritiva da aplicação da EAPE}

A Tabela 3 apresenta as frequências das respostas para cada questão do EAPE que contém um componente calibrado positivamente, assim como sua media, desvio padrão e a variância, sendo que foi atribuído um valor para cada resposta, sendo: 
discordo totalmente $=1$, discordo parcialmente $=2$, indiferente $=3$, concordo parcialmente $=4$ e concordo totalmente $=5$. Por outro lado, a Tabela 4 apresenta as frequências das respostas da EAPE que contém um componente calibrado negativamente, a media, desvio padrão e variância, neste caso os valores são alterados para cada resposta, sendo que quanto maior a discordância melhor: discordo totalmente $=5$, discordo parcialmente $=4$, indiferente $=3$, concordo parcialmente $=2$ e concordo totalmente $=1$.

Tabela 3 - Respostas Calibradas Positivamente

\begin{tabular}{lcccccccc}
\hline & \multicolumn{4}{c}{ Quantidade de respostas* } & \multicolumn{3}{c}{ Medidas Descritivas } \\
\hline \multirow{2}{*}{ Item } & $\begin{array}{c}\text { Discordo } \\
\text { Totalmente }\end{array}$ & $\begin{array}{c}\text { Discordo } \\
\text { Parcialmente }\end{array}$ & Indiferente & $\begin{array}{c}\text { Concordo } \\
\text { Parcialmente }\end{array}$ & $\begin{array}{c}\text { Concordo } \\
\text { Totalmente }\end{array}$ & $\begin{array}{c}\text { Média } \\
\text { Desvio } \\
\text { Padrão }\end{array}$ & Variância \\
\hline V1 & 0 & 0 & 0 & 8 & 8 & 4,5 & 0,516 & 0,266 \\
V2 & 0 & 0 & 0 & 2 & 14 & 4,875 & 0,341 & 0,116 \\
V3 & 0 & 0 & 0 & 2 & 14 & 4,875 & 0,341 & 0,116 \\
V5 & 0 & 0 & 0 & 2 & 14 & 4,875 & 0,341 & 0,116 \\
V8 & 1 & 0 & 0 & 2 & 13 & 4,625 & 1,024 & 1,05 \\
V9 & 1 & 0 & 2 & 6 & 7 & 4,125 & 1,087 & 1,183 \\
V11 & 0 & 0 & 0 & 2 & 14 & 4,875 & 0,341 & 0,116 \\
V12 & 0 & 1 & 5 & 5 & 5 & 3,875 & 0,957 & 0,916 \\
V13 & 0 & 2 & 1 & 3 & 10 & 4,315 & 1,078 & 1,162 \\
V14 & 0 & 0 & 0 & 6 & 10 & 4,625 & 0,5 & 0,25 \\
V15 & 0 & 0 & 4 & 7 & 5 & 4,062 & 0,771 & 0,595 \\
V18 & 0 & 0 & 0 & 10 & 6 & 4,375 & 0,5 & 0,25 \\
V19 & 0 & 0 & 0 & 5 & 11 & 4,687 & 0,478 & 0,229 \\
V20 & 0 & 0 & 0 & 6 & 10 & 4,625 & 0,5 & 0,25 \\
\hline \multicolumn{7}{l}{ Média Geral das estatísticas descritivas } \\
\hline \multicolumn{7}{l}{ Fonte: Elaborado pelos autores. }
\end{tabular}

Tabela 4 - Respostas Calibradas Negativamente

\begin{tabular}{lcccccccc}
\hline & \multicolumn{4}{c}{ Quantidade de respostas* } & \multicolumn{3}{c}{ Medidas Descritivas } \\
\hline Item & $\begin{array}{c}\text { Discordo } \\
\text { Totalmente }\end{array}$ & $\begin{array}{c}\text { Discordo } \\
\text { Parcialmente }\end{array}$ & Indiferente & $\begin{array}{c}\text { Concordo } \\
\text { Parcialmente }\end{array}$ & $\begin{array}{c}\text { Concordo } \\
\text { Totalmente }\end{array}$ & Média & $\begin{array}{c}\text { Desvio } \\
\text { Padrão }\end{array}$ & Variância \\
\hline V4 & 12 & 4 & 0 & 0 & 0 & 4,75 & 0,447 & 0,2 \\
V6 & 14 & 1 & 0 & 1 & 0 & 4,75 & 0,774 & 0,6 \\
V7 & 14 & 1 & 0 & 0 & 1 & 4,687 & 1,014 & 1,029 \\
V10 & 6 & 2 & 1 & 4 & 3 & 3,25 & 1,653 & 2,73 \\
V16 & 13 & 2 & 0 & 1 & 0 & 4,687 & 0,793 & 0,629 \\
V17 & 14 & 2 & 0 & 0 & 0 & 4,875 & 0,341 & 0,116 \\
V21 & 10 & 5 & 0 & 1 & 0 & 4,5 & 0,816 & 0,666 \\
\hline \multicolumn{2}{l}{ Média Geral das estatísticas descritivas } & & & & 4,428 & 0,834 & 0,853 \\
\hline
\end{tabular}

Fonte: Elaborado pelos autores.

Pode-se observar que, em geral, há uma coerência (concordância) entre as respostas dos professores tanto as calibradas positivamente (tabela 3) quanto às calibradas negativamente (tabela 4). A avaliação geral foi positiva com relação às 
variáveis da escala EAPE. Na tabela 3 verificou-se que quase todas médias foram altas, sendo que a média geral foi de 4,522. Somente a questão 11 que é referente à afirmação "Respondo com maturidade quando meus alunos fazem uma pergunta" que obteve um valor médio menor $(3,875)$. Essa variável, em especial pode ser um reflexo de quando os professores ainda eram estudantes, de maneira que exigem certos comportamentos dos alunos, assim como na sua época (ESTRADA; BATANERO; LANCASTER, 2011).

Da mesma forma a tabela 4 que traz as respostas calibradas negativamente mostrou resultados positivos, sendo encontrada uma média geral de 4,428. Quase todas médias foram altas, com exceção da questão 10 que é “Podemos manipular a realidade através da Estatística" que obteve um valor médio menor $(3,25)$ e a mais elevada variabilidade entre todos os itens. Partindo desses resultados é possível perceber que para alguns professores a estatística pode manipular a realidade e para outros não. Segundo Oliveira Junior (2016) a estatística não deve mascarar a verdade, como profissionais deve-se manter a ética na utilização da estatística sempre. No entanto, a interpretação desse item pode ter um viés subjetivo, uma vez que a estatística pode ser usada para manipular a realidade, no sentido de que é possível que isso ocorra, mas não necessariamente que isso deveria ocorrer, eticamente. Portanto, alguns professores podem ter interpretado "podemos" no sentido de "é possível" e outros podem ter interpretado no sentido de "devemos".

Alguns resultados mostraram-se extremamente positivos, foi o caso das variáveis 2, 3,5, 11 e 17. Essas variáveis demonstraram uma média de 4,875 e esse valor representa segundo a EAPE um resultado que favorece aos alunos, aos cursos e ao próprio professor. Para Martins (2015) quando um professor tem seus métodos e comportamentos alinhados a suas atitudes positivas (neste estudo) é possível que o aluno crie uma imagem positiva do seu professor facilitando o processo de ensino.

A Figura 4 apresenta a média dos itens segundo o gênero. Observa-se que, em geral ( $81 \%$ dos itens), as professoras, possuem uma concordância média levemente maior que os professores, com uma média geral de concordância de 4,64 contra 4,44. 
Figura 4 - Média dos itens por gênero

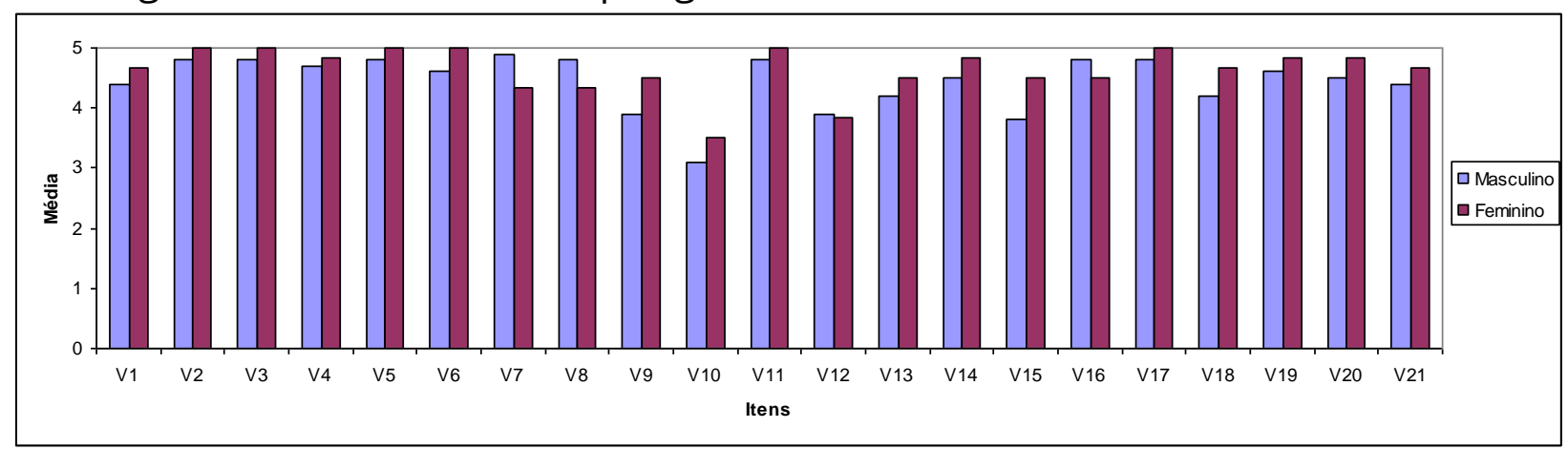

Fonte: Elaborado pelos autores.

A Figura 5 apresenta a média dos itens segundo o tempo de atuação docente. Como mencionado anteriormente, foram identificados dois grupos de docentes: 16 docentes com até 16 anos de carreira docente e 5 docentes com pelo menos 28 anos de carreira docente. Observa-se que, parece não haver muita diferença entre as médias desses grupos, sendo que média geral de concordância foi bem próxima entre eles: 4,51 para o grupo de menor experiência contra 4,52 para o grupo mais experiente. No entanto, os professores mais jovens parecem concordar mais com as afirmações "o pensamento estatístico é tão necessário para a cidadania eficiente como saber ler e escrever" e "é importante apresentar conceitos básicos da Estatística Bayesiana". Já os professores mais experientes foram unânimes em discordar com a afirmação " utilizo a Estatística exclusivamente para dar aulas", o que implica que eles devem utilizar a estatística em outras esferas da educação superior, tais como a Pesquisa e a Extensão.

Figura 5 - Média dos itens por tempo de atuação docente

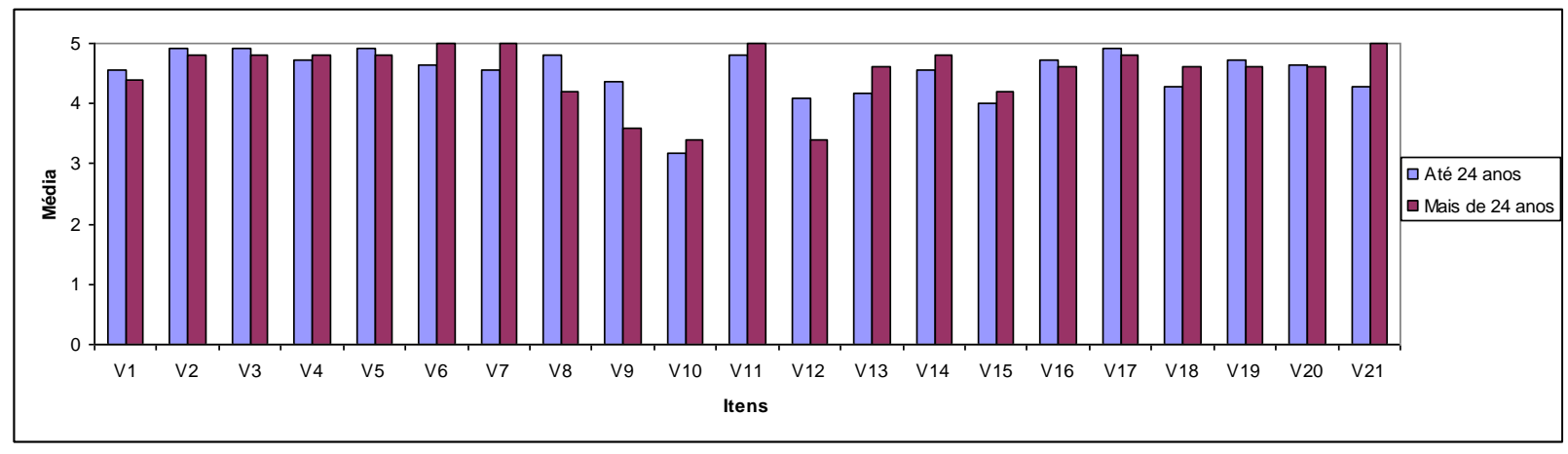

Fonte: Elaborado pelos autores. 
A Figura 6 apresenta a média dos itens segundo o estado civil (solteiros e divorciados foram agrupados numa única categoria, pois havia apenas um divorciado na amostra). Observa-se que, parece não haver muita diferença entre as médias desses grupos, sendo que média geral de concordância foi bem próxima entre eles: 4,50 para os casados contra 4,54 dos solteiros e divorciados. Professores solteiros parecem concordar mais com as afirmações "o pensamento estatístico é tão necessário para a cidadania eficiente como saber ler e escrever" e " devo desenvolver atividades com dados reais utilizando minha experiência".

Figura 6 - Média dos itens por estado civil

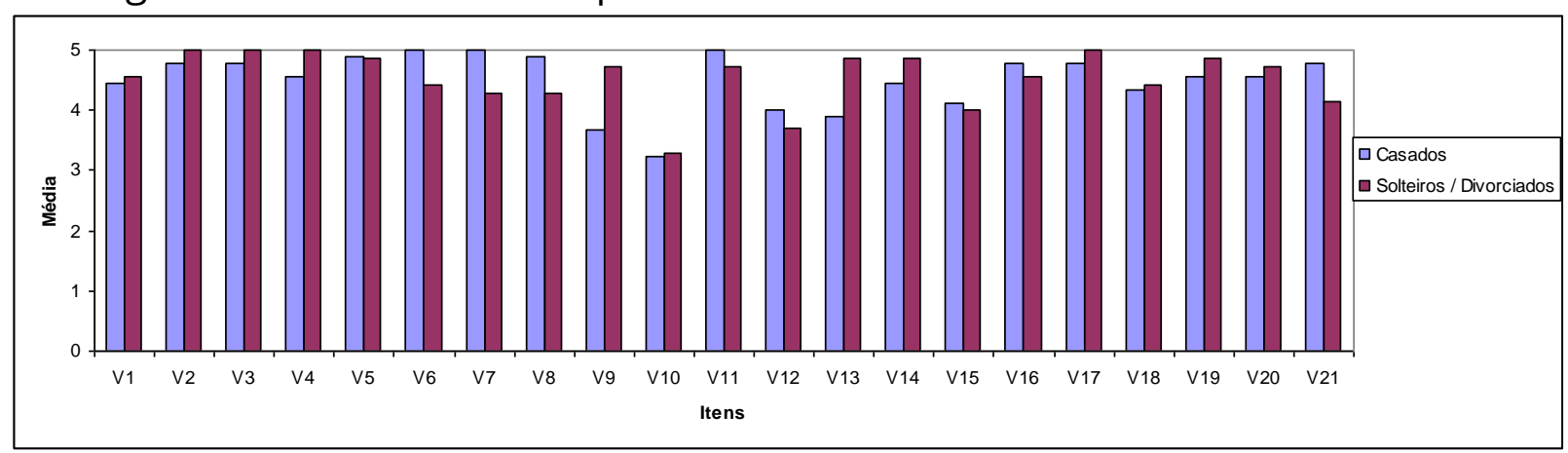

Fonte: Elaborado pelos autores.

Na tabela 5 estão dispostos as concordâncias médias dos 15 itens da EAPE15, distribuídas conforme os domínios de análise da escala EAPE15, definidos por Oliveira Junior (2016), e a componente inicial da escala EAPE. Também estão dispostos os escores relativos obtidos por Oliveira Junior (2016) criados numa escala entre 0 e 100. Para fins de comparação, esses escores relativos foram colocados na escala likert utilizada nesse estudo, entre 1 e 5, por meio de uma transformação linear de mudança de escala. 
Tabela 5 - Concordância média segundo os domínios da Escala EAPE15

\begin{tabular}{|c|c|c|c|c|c|c|c|}
\hline \multirow{2}{*}{$\begin{array}{l}\text { Item da } \\
\text { Escala EAPE }\end{array}$} & \multirow{2}{*}{$\begin{array}{l}\text { Componente Inicial } \\
\text { da escala EAPE }\end{array}$} & \multicolumn{6}{|c|}{ Domínios da Escala EAPE15 } \\
\hline & & Valorização & Afetividade & Ensino & Conteúdo & Método & Abstração \\
\hline 20 & $\begin{array}{l}\text { Comportamental e } \\
\text { Instrumental }\end{array}$ & 4,625 & & & & & \\
\hline 19 & Afetivo e Social & 4,687 & & & & & \\
\hline 11 & $\begin{array}{c}\text { Comportamental e } \\
\text { Educativo }\end{array}$ & 4,875 & & & & & \\
\hline 17 & $\begin{array}{c}\text { Afetivo e } \\
\text { Instrumental }\end{array}$ & & 4,875 & & & & \\
\hline 16 & Afetivo e Social & & 4,687 & & & & \\
\hline 21 & Cognitivo e Social & & 4,5 & & & & \\
\hline 2 & $\begin{array}{l}\text { Cognitivo e } \\
\text { Instrumental }\end{array}$ & & & 4,875 & & & \\
\hline 13 & Cognitivo e Educativo & & & 4,315 & & & \\
\hline 3 & Cognitivo e Educativo & & & 4,875 & & & \\
\hline 4 & Cognitivo e Educativo & & & & 4,75 & & \\
\hline 7 & $\begin{array}{l}\text { Cognitivo e } \\
\text { Instrumental }\end{array}$ & & & & 4,687 & & \\
\hline 14 & $\begin{array}{l}\text { Cognitivo e } \\
\text { Instrumental }\end{array}$ & & & & & 4,625 & \\
\hline 15 & $\begin{array}{l}\text { Comportamental e } \\
\text { Instrumental }\end{array}$ & & & & & 4,062 & \\
\hline 5 & Cognitivo e Educativo & & & & & & 4,875 \\
\hline 12 & Cognitivo e Educativo & & & & & & 3,875 \\
\hline & lédia Geral & 4,729 & 4,687 & 4,688 & 4,718 & 4,343 & 4,375 \\
\hline $\begin{array}{r}\text { Escores } r \\
\text { Olive }\end{array}$ & $\begin{array}{l}\text { elativos obtidos por } \\
\text { ira Junior (2016) }\end{array}$ & 86,6 & 89,5 & 89,3 & 89,4 & 81,6 & 75,8 \\
\hline $\begin{array}{r}\text { Escores de } \\
\text { na }\end{array}$ & $\begin{array}{l}\text { Oliveira Junior (2016) } \\
\text { escala likert }\end{array}$ & 4,464 & 4,580 & 4,572 & 4,576 & 4,264 & 4,032 \\
\hline
\end{tabular}

A escala EAPE15 surgiu através dos estudos de Oliveira Junior (2016) como forma de melhorar a escala EAPE, onde a escala EAPE15 é composta por alguns dos itens da EAPE.

Nesta analise todas as médias demonstraram resultados satisfatórios com relação aos seis domínios investigados. Ao fazer a comparação na mesma escala, as médias gerais de concordância dos seis domínios foram superiores às médias que Oliveira Junior (2016) encontrou em sua pesquisa. Esse resultado pode ter ocorrido em função de que todos os professores que responderam a pesquisa fazem parte do corpo docente de um departamento de estatística, de maneira que na coleta de Oliveira Junior observou somente o ensino de estatística onde o professor poderia estar alocado em outro departamento. 


\subsection{Análise de correlação}

Foram realizados os cálculos referentes à correlação entre as variáveis: Idade dos professores (X1), Tempo de atuação (X2), Média de alunos por turma (X3), e todos os 21 itens que compõem a Escala de Atitudes de Professores de Estatística (EAPE) correspondentes aos itens V1 até V21. A Figura 7 mostra a matriz de correlação dessas variáveis com a intensidade da correlação. Nesta tem-se as variáveis correlacionadas, que indicam através de uma paleta de cores, na qual a tonalidade mais forte de azul nos mostra uma relação fortemente negativa, a tonalidade vermelha nos mostra uma relação fortemente positiva e os resultados mais claros indicam a ausência de correlação, e as caselas em branco indicam a correlação igual à zero, assim como mostra a legenda ao lado da Figura 7.

A análise realizada no software R e apresentada na Figura 7, apesar de indicar a intensidade das correlações, não indica quais são as correlações significativas. Para verificar isso, foi realizada uma análise complementar no SPSS, apresentada no Quadro 7, o qual mostra a mesma matriz de correlação da Figura 7, porém com o resultado do teste de hipótese bilateral para a significância da correlação. Foram encontradas 24 correlações significativas entre as variáveis.

Observa-se uma correlação perfeita e positiva entre as variáveis V2 e V3, "É importante desenvolver pesquisas para que os alunos possam fazer as relações entre a teoria e a prática" e "Fazer perguntas aos alunos durante as aulas ajuda na apreensão do conteúdo". Considerando essa correlação com a Tabela 3, chega-se a conclusão que os professores responderam as mesmas respostas nessas duas questões. Isso significa que realmente, quanto mais os professores perguntam aos alunos sobre o conteúdo, fazendo com que eles entendam, mais eles consideram importante colocar em prática a teoria nas pesquisas.

Essas duas variáveis também possuem correlação inversa perfeita com a variável V17 "Evito ler artigos científicos onde são apresentados resultados estatísticos". Isso significa que os professores que consideram importante desenvolver pesquisas para que os alunos possam fazer as relações entre a teoria e a prática e que acham que fazer perguntas aos alunos durante as aulas ajuda na apreensão do conteúdo não evitam ler 
artigos científicos onde são apresentados resultados estatísticos, ou seja, consideram importante desenvolver pesquisas e lêem artigos científicos da área.

As variáveis V2 e V3 ainda possuem correlação significativa direta com a V9 "O pensamento estatístico é tão necessário para a cidadania eficiente como saber ler e escrever" e com a V13 (Devo desenvolver atividades com dados reais utilizando minha experiência). Esses professores que desenvolvem pesquisas e fazem perguntas aos alunos durante as aulas consideram essencial o pensamento estatístico e utilizar dados reais nas atividades desenvolvidas.

A variável V17 "Evito ler artigos científicos onde são apresentados resultados estatísticos" possui correlação significativa inversa com a V9 “O pensamento estatístico é tão necessário para a cidadania eficiente como saber ler e escrever" e com a V13 "Devo desenvolver atividades com dados reais utilizando minha experiência". Assim, professores que evitam ler artigos científicos não consideram o pensamento estatístico essencial e nem utilizam dados reais nas atividades desenvolvidas.

A variável V4 "Não me parece importante relacionar novos conhecimentos com conteúdo anteriormente aprendido" se correlaciona negativamente com a V13 "Devo desenvolver atividades com dados reais utilizando minha experiência". Dessa forma, docentes que relacionam novos conhecimentos com conteúdo anteriormente aprendido também desenvolvem atividades com dados reais.

Figura 7 - Matriz de correlação entre as variáveis de atitude EAPE

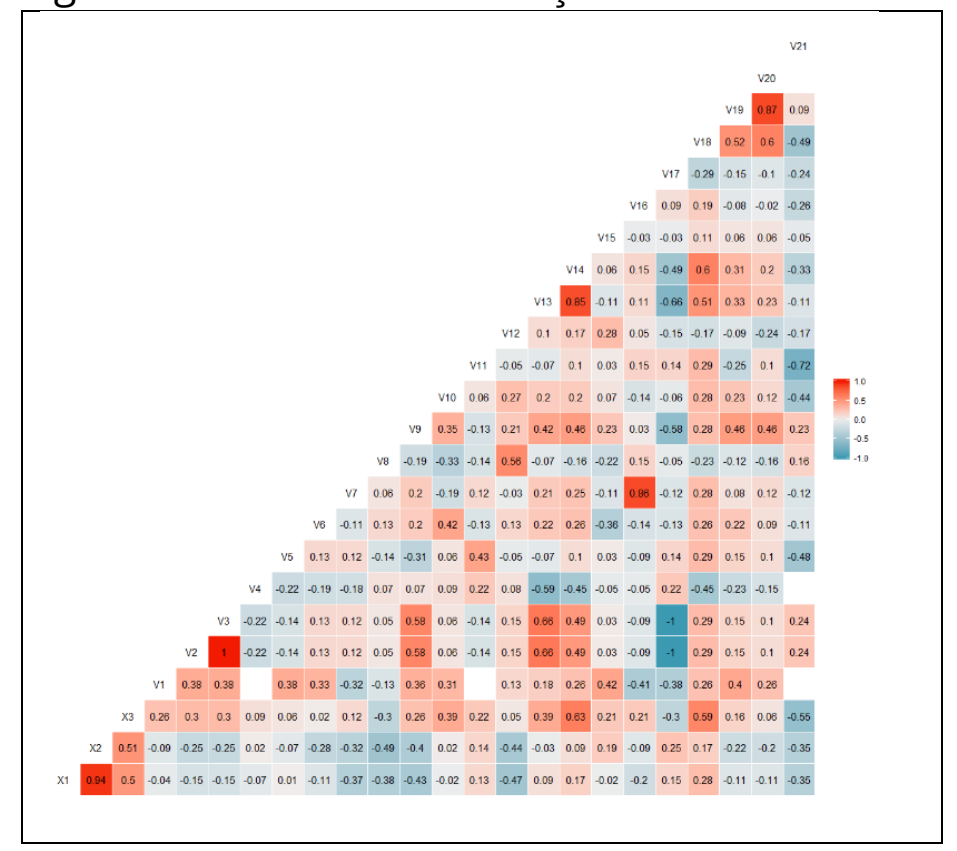

Fonte: Elaborado pelos autores por meio do software R. 
A V7 (A representação gráfica não facilita a compreensão dos resultados estatísticos) obteve correlação significativa direta com a V16 (Evito as informações estatísticas quando as leio). As duas perguntas são inversas, com isso professores que consideram que a representação gráfica é uma informação chave para a compreensão dos dados não evitam as informações estatísticas quando as lêem.

A V8 (Motivar os alunos ajuda na aprendizagem da Estatística) demonstrou correlação positiva significativa com V12 (É importante apresentar conceitos básicos da Estatística Bayesiana). Professores que consideram importante os conceitos de Estatística Bayesiana também motivam seus alunos na aprendizagem.

Quadro 7 - Matriz de correlações

\begin{tabular}{|c|c|c|c|c|c|c|c|c|c|c|c|c|c|c|c|c|c|c|c|c|c|c|c|c|}
\hline & $\mathrm{X} 1$ & $\times 2$ & $\times 3$ & V1 & V2 & V3 & V4 & V5 & V6 & V7 & V8 & V9 & V10 & V11 & V12 & V13 & V14 & V15 & V16 & V17 & V18 & V19 & V20 & V21 \\
\hline $\mathrm{X} 1$ & 1,0 & & & & & & & & & & & & & & & & & & & & & & & \\
\hline $\mathrm{X3}$ & 0,5 & $0,5^{*}$ & 1,0 & & & & & & & & & & & & & & & & & & & & & \\
\hline V1 & 0,0 & $-0,1$ & 0,3 & 1,0 & & & & & & & & & & & & & & & & & & & & \\
\hline V3 & $-0,2$ & $-0,2$ & 0,3 & 0,4 & $1,0^{\star *}$ & 1,0 & & & & & & & & & & & & & & & & & & \\
\hline V4 & $-0,1$ & 0,0 & 0,1 & 0,0 & $-0,2$ & $-0,2$ & 1,0 & & & & & & & & & & & & & & & & & \\
\hline V5 & 0,0 & $-0,1$ & 0,1 & 0,4 & $-0,1$ & $-0,1$ & $-0,2$ & 1,0 & & & & & & & & & & & & & & & & \\
\hline V8 & $-0,4$ & $-0,5$ & $-0,3$ & $-0,1$ & 0,0 & 0,0 & 0,1 & $-0,1$ & 0,1 & 0,1 & 1,0 & & & & & & & & & & & & & \\
\hline V9 & $-0,4$ & $-0,4$ & 0,3 & 0,4 & $0,6^{*}$ & $0,6^{*}$ & 0,1 & $-0,3$ & 0,2 & 0,2 & $-0,2$ & 1,0 & & & & & & & & & & & & \\
\hline V10 & 0,0 & 0,0 & 0,4 & 0,3 & 0,1 & 0,1 & 0,1 & 0,1 & 0,4 & $-0,2$ & $-0,3$ & 0,4 & 1,0 & & & & & & & & & & & \\
\hline V11 & 0,1 & 0,1 & 0,2 & 0,0 & $-0,1$ & $-0,1$ & 0,2 & 0,4 & $-0,1$ & 0,1 & $-0,1$ & $-0,1$ & 0,1 & 1,0 & & & & & & & & & & \\
\hline V12 & $-0,5$ & $-0,4$ & 0,0 & 0,1 & 0,2 & 0,2 & 0,1 & $-0,1$ & 0,1 & 0,0 & $0,6^{*}$ & 0,2 & 0,3 & $-0,1$ & 1,0 & & & & & & & & & \\
\hline V13 & 0,1 & 0,0 & 0,4 & 0,2 & $0,7 \star \star$ & $0,7^{\star \star}$ & $-0,6^{*}$ & $-0,1$ & 0,2 & 0,2 & $-0,1$ & 0,4 & 0,2 & $-0,1$ & 0,1 & 1,0 & & & & & & & & \\
\hline V19 & $-0,1$ & $-0,2$ & 0,2 & 0,4 & 0,2 & 0,2 & $-0,2$ & 0,2 & 0,2 & 0,1 & $-0,1$ & 0,5 & 0,2 & $-0,3$ & $-0,1$ & 0,3 & 0,3 & 0,1 & $-0,1$ & $-0,2$ & $0,5^{*}$ & 1,0 & & \\
\hline $\mathrm{V} 20$ & $-0,1$ & $-0,2$ & 0,1 & 0,3 & 0,1 & 0,1 & $-0,1$ & 0,1 & 0,1 & 0,1 & $-0,2$ & 0,5 & 0,1 & 0,1 & $-0,2$ & 0,2 & 0,2 & 0,1 & 0,0 & $-0,1$ & $0,6^{*}$ & $0,9^{* *}$ & 1,0 & \\
\hline V21 & $-0,3$ & $-0,4$ & $-0,6^{*}$ & 0,0 & 0,2 & 0,2 & 0,0 & $-0,5$ & $-0,1$ & $-0,1$ & 0,2 & 0,2 & $-0,4$ & $-0,7^{\star *}$ & $-0,2$ & $-0,1$ & $-0,3$ & $-0,1$ & $-0,3$ & $-0,2$ & $-0,5$ & 0,1 & 0,0 & 1,0 \\
\hline
\end{tabular}

A V13 (Devo desenvolver atividades com dados reais utilizando minha experiência) demonstrou também correlação direta com V14 (Vinculo a Estatística aos métodos e técnicas científicos) e V18 (Procuro diferentes maneiras de resolver um problema de Estatística)e inversa com V17 (Evito ler artigos científicos onde são apresentados resultados estatístico). Professores que utilizam dados reais vinculam a estatística aos métodos científicos, lêem artigos científicos e procuram diferentes maneiras de resolver um problema de Estatística. 
A V18 demonstra uma correlação positiva com V14, V19 (Gosto da Estatística porque ela ajuda a solucionar problemas objetivamente) e V20 (A Estatística me ajuda a entender mais profundamente a complexidade de certos tema) que demonstra que a resolução de um problema vista por outros ângulos reflete em uma busca complexa e objetiva. A V19 também demonstra uma forte correlação com a V20 que assim como na correlação anterior vincula a objetividade da estatística uma complexa gama de temas.

A variável V11 (Respondo com maturidade quando meus alunos fazem uma pergunta) está correlacionada inversamente com a V21 (Utilizo a Estatística exclusivamente para dar aula). Podemos concluir que os professores que respondem com maturidade quando meus alunos fazem uma pergunta também utilizam a Estatística fora da sala de aula, como em projetos de Pesquisa e Extensão.

A variável X3 (média de alunos por turma) demonstrou uma correlação positiva com a Variável V14 (Vinculo a Estatística aos métodos e técnicas científica) e V18 (Procuro diferentes maneiras de resolver um problema de Estatística) e negativa com a V21 (Utilizo a Estatística exclusivamente para dar aula). Esses resultados demonstram a que aspectos ligados a aplicação de estatística em sala de aula estão diretamente relacionadas ao número de alunos na turma, sendo que quanto mais alunos na turma, mais o professor procura desenvolver essas atividades (vincular à métodos científicos, resolver problemas de formas diferentes e utilizar a Estatística fora da sala de aula).

As variáveis V1 "É divertido lecionar estatística", V5 "Os alunos devem estar conscientes da importância do conhecimento matemático para a aprendizagem da Estatística", V6 "A aprendizagem da Estatística não pressupõe conhecimentos matemáticos", V10 "Podemos manipular a realidade através da Estatística" e V15 “Estudo e procuro explicações lógicas que comprovem as imprecisões apresentadas por autores de livros de Estatística" não tem nenhuma relação significativa com outras variáveis.

Com relação aos domínios da Escala EAPE15, perceberam-se algumas correlações interessantes: as variáveis V19 e V20 do domínio "valorização", e as variáveis V2, V3 e V20 do domínio "ensino". 


\section{CONSIDERAÇÕES FINAIS}

Conclui-se que o objetivo, que era conhecer as atitudes de professores do Departamento de Estatística em uma Universidade do sul do Brasil, utilizando a ferramenta EAPE e EAPE15, foi alcançado. O estudo mostrou que os professores do departamento investigado demonstram atitudes positivas ao ensino de estatística, facilitando o aprendizado e a compreensão entre os alunos.

De maneira às respostas dos professores foram positivas, as médias em geral demostraram resultados satisfatórios se comparados aos encontrados por Oliveira Junior (2016). Os professores na análise da EAPE demonstram que suas atitudes estão alinhadas a um ensino de qualidade para seus alunos. A grande maioria das questões mostram resultados positivos, para Martins (2015) quando um professor tem seus métodos e comportamentos alinhados a suas atitudes positivas, que é o caso deste estudo é possível que o aluno crie uma imagem positiva do seu professor facilitando o processo de ensino. Somente uma variável referente à resposta dos professores aos alunos não mostrou resultados tão positivos quanto os demais, segundo Estrada, Batanero e Lancaster (2011) tal variável pode ser um reflexo da vida discente dos professores e as exigências que eram feitas para eles.

Foi possível também perceber que alguns professores acreditam que através da estatística é possível manipular a realidade, embora Oliveira Junior (2016) diga que a estatística não deve mascarar a verdade e que deve-se manter a ética na utilização da estatística sempre. Todavia a interpretação desse item pode ter tido um viés subjetivo, pois alguns professores podem ter interpretado "podemos" no sentido de "é possível (embora não seja o correto)" e outros podem ter interpretado no sentido de "devemos".

$\mathrm{Na}$ análise dos resultados referentes aos domínios da EAPE15, todas as concordâncias médias apresentaram valores maiores quando comparados aos que Oliveira Junior (2016) encontrou em sua pesquisa. Esse resultado pode ter ocorrido em função de que todos os professores da Universidade investigada que responderam a pesquisa fazem parte do corpo docente de um departamento de estatística, enquanto que no estudo de Oliveira Junior (2016) podem ter docentes de outros departamentos 
que, embora ministrem disciplina de estatística, podem não ter uma atitude tão positiva quanto à estatística.

$\mathrm{Na}$ análise de correlação, pode-se ser visualizado que algumas das variáveis se correlacionam de maneira positiva e negativa (devido ao fato de existirem perguntas com opções reversas) e isso vai de encontro aos estudos de Oliveira Junior (2016). Por outro lado, alguns itens não demonstram correlação significativa com nenhum outro item em especial, isso pode estar relacionado com a falta de entendimento das afirmações, como no caso do item "Podemos manipular a realidade através da Estatística", discutido anteriormente. 


\section{REFERÊNCIAS}

AUZMENDI EE. Las actitudes hacia la matemática estadística en las enseñanzas medias y universitarias. Bilbao: Mensajero, 1992.

CARMONAJM. Una revisión de las evidencias de fiabilidad e validez de los cuestionarios de actitudes y ansiedad hacia la Estadística. Statistics Education Research Journal, 2004, 3(1): 5-28.

CAZORLA IM, SILVA CB, VENDRAMINI CMM, BRITO MRF. Adaptação e validação de uma escala de atitudes em relação à estatística. In: Conferência Internacional: Experiências e Perspectivas do Ensino da Estatística - Desafios para o século XXI, 1., 1999, Florianópolis, Santa Catarina. Anais..., UFSC, Florianópolis, 1999.

CHANG L. Quantitative attitudes questionnaire: instrument development and validation. Educational and Psychological Measurement, 1996, 56(6): 1037-1042.

ESTRADA A. Instrumentos de medicion de actitudes hacia la estadistica: la escala EAEE para profesores. In: MORENO MM, CLIMENT N. (Eds.). Investigación en Educación Matemática. Comunicaciones de los Grupos de Investigación de la SEIEM, Lleida, 2011.

ESTRADA A, BATANERO C, FORTUNY JM. Actitudes y estadistica en profesores en formación y en ejercicio. In: congreso nacional de estadística e investigación operativ, 27, 2003, Lleida: Edicions de la Universitat de Lleida, 2003.

ESTRADA A, BAZÁN J, APARICIO AS. A Evaluación de las propiedades psicométricas de una escala de actitudes hacia la estadística en profesores. Avances de Investigación en Educación Matemática, 2013, 3: 5-23.

ESTRADA A, BATANERO C, LANCASTER S. Teachers' Attitudes Towards Statistics. In: BATANERO C, BURRIL G, READING C. (Eds.). Teaching Statistics in School Mathematics - Challenges for Teaching and Teacher Education: A Joint ICMI/IASE Study. Dordrecht: Springer Science+Business Media, 2011: 163-174.

GAL I, GINSBURG L. The role of beliefs and attitudes in learning statistics: Toward an assessment framework. Journal of Statistics Education, 1994, 2(2).

GIL FLORES J. Actitudes hacia la Estadística. Incidencia de las variables sexo y Educ. Revista Española de Pedagogía, Madrid, Espanha, 1999, (214): 567- 590.

GÓMEZ CHACÓN IM. Matemática emocional. Los afectos en el aprendizaje matemático. Madrid, España: Narcea, 2000.

LIKERT R. A technique for the measurement of attitudes. Arquives of Psychology, 1932, (140): 1-50. 
MARTINS JASVM. Estudo das atitudes em relação à Estatística dos professores do $1^{\circ}$ ciclo e dos professores de Matemática do $2^{\circ}$ ciclo do ensino básico. $2015.567 \mathrm{f}$. Tese (Doutorado em Didática de Ciências e Tecnologias) - Universidade de Trás-osMontes e Alto Douro, Portugal, 2015.

MCCALL CH, MADJIDI F, BELLI G. The complexities of the teaching graduate students in educational administration introductory statistical concepts. PICTeachSt3, 1991, 2: 495-497.

MILLER RB, BEHRENS JT, GREEN BA, NEWMAN D. Goals and perceived ability: Impact on student valuing, self-regulation and persistence. Contemporary Educational Psychology, 1993, 18: 2-14.

OLIVEIRA JÚNIOR AP, MORAIS JF. Validação da Escala de Atitudes de Professores de Estatística em Relação à Estatística no Ensino Superior no Brasil. Revista Ciência \& Educação, 2009, 15(3): 581-591.

OLIVEIRA JÚNIOR AP. Avaliação de atitudes, características pessoais, utilização de tecnologias e prática docente de professores de graduação em estatística. Educ. Matem. Pesq. 2011, 13(2): 253-272.

OLIVEIRA JÚNIOR AP. A Escala de Atitudes em relação ao Ensino de Estatística de professores do Ensino Superior no Brasil. Educ. Matem. Pesq. 2016, 18(3): 1449-1463.

ROBERTS DM, BILDERBACK EW. Reliability and Validity of a Statistics Attitude Survey. Educational and Psychological Measurement, 1980, 40: 235-238.

SCHAU C, STEVENS J, DAUPHINE T, DEL VECCHIO A. The development and validation of the survey of attitudes towards statistics. Educational and Psychological Measurement, 1995, 55(5): 868-875.

SUTARSO T. Some variables in relation to students' anxiety in learning statistics. In: Annual Meeting of the Mid-South Educational Research Association, Knoxville, TN, EE. UU, 1992.

TISHKOVSKAYA S, LANCASTER G. Statistical Education in the 21st Century: a Review of Challenges, Teaching Innovations and Strategies for Reform. Journal of Statistics Education, 2012, 20(2): 1-24.

VELANDRINO AP, PARODI LH. La Escala de Actitudes Hacia la Estadística (EAE): Desarrollo y Propiedades Psicométricas. In: Conferência Internacional Experiências e Expectativas do Ensino da Estatística: Desafios para o Século XXI, 1., 1999, Florianópolis, Brasil. Anais ..., UFSC, Florianópolis, Brasil, 1999. 
WISE SL. The development and validation of a scale measuring attitudes toward statistics. Educational and Psychological Measurement, 1985, 45: 401-405. 15. 